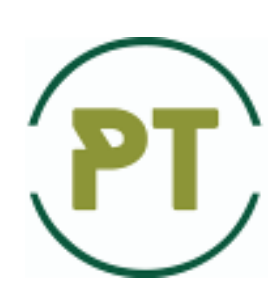

\title{
Investigation of tribological characteristics of brake pairs elements of mobile machine
}

\author{
V. Jankauskas, D. Kairiūnas \\ Vytautas Magnus university, Lithuania \\ *E-mail:vytenis.jankauskas@vdu.lt
}

Received: 22 April 2021: Revised: 14 July: Accept: 23 August 2021

\begin{abstract}
The subject of the experiments was the tribological properties of typical brake pads and disc characteristics. For the experiment was used Grey Cast Iron brake disc and semi metallic, low steel quantity and ceramic brake pads. The breaking process was imitated. The experiment was conducted at $0.75,1.25$ and $1.76 \mathrm{~m} / \mathrm{s}$ sliding speed using $0.85 \mathrm{MPa}$ contact pressure. The experiments lasted 10 minutes. The results of the experiments showed that best tribological characteristics have ceramic brake pads, despite the fact that brake disc temperature rapidly increase the with ceramic brake pads, but the friction coefficient (and braking torque) was the best. Semi metallic and low steel braking pads had very similar friction coefficient values, but wear and disc temperature values were more dissimilar.
\end{abstract}

Key words: brake system, pads, disc, material, coefficient of friction, wear.

\section{Introduction}

According to the data of the Department of Statistics of the Republic of Lithuania, the total number of vehicles is increasing by $\sim 5 \%$ annually, which affects traffic safety and environmental pollution [1]. More than 1.5 million vehicles are registered in Lithuania. The volumes of mobile construction and agricultural machinery are constantly increasing.

Vehicles pollute the environment not only with exhaust gases but also with wear products on the road surface, tires and brake system. Brake pads are one of the most wearing and polluting parts of a car [2, 3]. Brake system wear products can cause for as much as $90 \%$ of vehicle pollution, and about $35 \%$ of wear products are potentially released into the environment.

The main function of the braking system is to decelerate and / or stop the vehicle. When braking, the kinetic energy of the mobile machine is converted into heat. The intensity of heat release depends on the weight of the mobile machine, the speed of movement, the intensity of braking.

The brake system is one of the key safety features of a car [4]. During braking, there is friction, which results in active wear of the friction and disc surfaces of the brake pads [5]. When the brake discs and pads are heated, the coefficient of friction changes, which affects the stability of the braking system.

\section{Literature review}

The brake discs absorb most of the heat generated by the braking and their temperature rises from 20 to $700{ }^{\circ} \mathrm{C}$ in a few seconds. The material of the brake discs must be such as to withstand not only the normal mechanical load produced during braking but also the operating temperature. The following types of brake discs are distinguished according to their predominant composition [2].

1. Carbon fiber discs. These are discs with excellent thermal and mechanical properties, but due to their high cost they are not practical for everyday use (used in aviation, sports).

2. Aluminium alloy discs are extremely light, such as Aluminium-Copper alloy (Al-Cu), but their thermal conductivity is too low, so their use is limited. 
3. Cast iron brake discs are most popular in mobile machines due to their good physical-mechanical properties, good price-quality ratio, such as Gray Cast Iron (GCI).

The main requirements for "friction-disc" brake friction pairs are: constant friction coefficient, low wear rate (possibly lower particulate emissions), quiet operation [6]. Brake element manufacturers do not provide material information (except for an indication of the material group to which the product belongs). The manufacturer shall specify only the vehicle model for which this item is intended.

Friction material is the most important element influencing the performance of the brake friction pair. Brake pads are divided into Organic / Low Steel Quantity / Non Asbestos Organic, Semi-Metallic and Ceramic according to the composition of the friction material [3]. There are many requirements for friction material. It must have the following characteristics [4]: stable coefficient of friction (little influence on speed and temperature); high operating temperature and resistance to abrasion, cracks; tribologically matched to metal parts; work quietly (without vibrations); adequate resistance to compressive and shear loads and to water, oil, salts or dirt; "Environmentally friendly"; inexpensive and technological.

The low metal quantity brake lining contains $5-35 \%$ non-ferrous metals. The coefficient of friction is in the range of $0.38-0.50$. They are ideal for high speed operation [7]. Organic brake pads are made of a mixture of common materials like rubber, carbon, glass / fiberglass and others, binded by resin.

Semi-metallic models consist of between 30 and $65 \%$ metal.

Ceramic brake pads are free of metals and are made of metal oxides and carbides [8]. The coefficient of friction is in the range of $0.33-0.40$ [7]. The blocks are made of ceramic fibers and fillers of a similar type, these blocks are more wear resistant, creates less noise and last longer. An important drawback is that it only works effectively when warmed up to operating temperature.

The actual contact loads in passenger car brake systems are up to $150 \mathrm{~N} / \mathrm{cm}^{2}[9]$.

The composition, microstructure and wear parameters of brake discs are analyzed in the work [10]. The microstructure and composition of gray cast iron are shown in Figure 1.

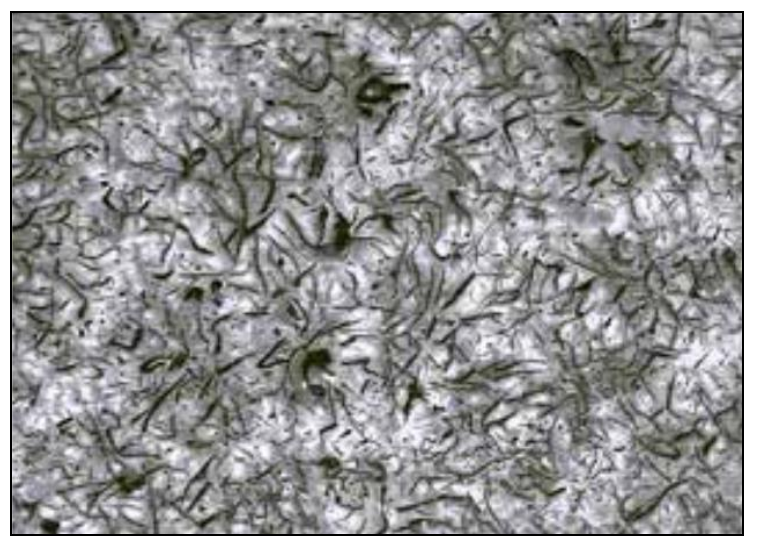

Fig. 1. Typical microstructure of gray cast iron disc brake (composition C 3.54\%, Si 2.08\% Mn 0.856\% S 0.14\% P 0.18\%) [10]

\section{Purpose}

The aim of the study was to investigate the tribological characteristics of friction pairs (brake disc - brake pad) - the influence of different friction pad materials and load on brake disc heating, friction coefficient and wear.

\section{Materials and Methods}

Experimental research was performed in the Tribology Laboratory of the Department of Mechanical, Energy and Biotechnology Engineering of Vytautas Magnus University.

Three brake pads of different materials were selected for the study: Semi metallic (hereinafter No. 1), Low Steel Quantity (hereinafter No. 2) and Ceramic (hereinafter No. 3) and cast-iron brake discs. The latter is made of AUDI A8 original cast iron brake discs (Gray Cast Iron). The dimensions of the discs are $\varnothing 65 \times \varnothing 16 \times$ $15 \mathrm{~mm}$ (Fig. 2). The weight of the discs is $\sim 275$ grams.

Laboratory tests of friction pairs were performed on a modernized tribological research machine СМЦ-2, in which two friction pads are symmetrically mounted symmetrically compress to the brake disc. This prevents the brake disc from bending and the axial load on the friction machine shaft.

The coefficient of friction $\mu$ is calculated by the expression:

$$
\mu=M /\left(2 \cdot F_{2} \cdot r_{\text {average }}\right) .
$$


here $r_{\text {average }}$ - distance from the centre of the brake lining to the axis of rotation of the brake disc, m;

$F_{2}$ - force of pressure of friction blocks to the disc, N;

$M-$ is the registered braking torque of the test machine, $\mathrm{Nm}$.

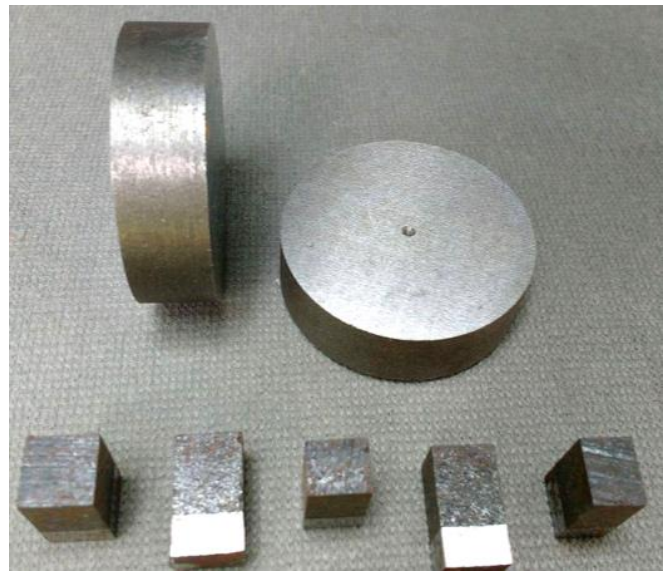

Fig. 2. Friction pads $14 \times 14 \times 20 \mathrm{~mm}$ (cut from brake pads) and gray cast iron blanks $(670 \times 15 \mathrm{~mm}$ dises $)$ for the manufacture of brake discs

The difference in friction surface areas was up to $3 \%$ (block No. 1 area $196 \mathrm{~mm}^{2}$, No. $2-189 \mathrm{~mm}^{2}$, No. $3-189 \mathrm{~mm}^{2}$ ). The weight of the blocks is $\sim 12$ grams. To determine the wear of the friction pairs, the discs and pads were weighed before and after the test with a KERN EG420 scale to the nearest $1 \mathrm{mg}$. The tests were repeated three times.

The tests were performed at sliding speeds of $0.75,1.25$ and $1.76 \mathrm{~m} / \mathrm{s}$. A contact load of $0.85 \mathrm{MPa}$ brake lining was used in the study. The temperature of the brake disc was measured with a non-contact thermometer G900IR before and during the test (measured every 2 min intervals). The test duration of test was 10 min, chosen due to the relatively low mass of the disc (heat capacity).

\section{Results}

The wear results of the brake discs and pads are shown in the diagram (Figure 3). The higher the speed at which the brake pads of different materials operate, the greater and more uniform their wear (from 0.093 to $0.103 \mathrm{~g}$ at a sliding speed of $1.76 \mathrm{~m} / \mathrm{s}$ ). Ceramic blocks wear loss at $0.75 \mathrm{~m} / \mathrm{s}$ is lower by $47 \%$ compared to semi metallic blocks, but wear loss at $1176 \mathrm{~m} / \mathrm{s}$ and higher by $11 \%$. The main advantage of ceramic blocks is seen at a sliding speed of $1.25 \mathrm{~m} / \mathrm{s}$, at which these blocks wear loss is $0.045 \mathrm{~g}$, and blocks of other materials varied in the range of $0.082-0.095 \mathrm{~g}$.

At all working speeds, cast iron brake discs used with ceramic pads showed greater wear resistance (up to 3.8 times less) than discs used with pads of other tested materials (Fig. 3).

The temperature change of the brake discs during the test is shown in Figure 4.

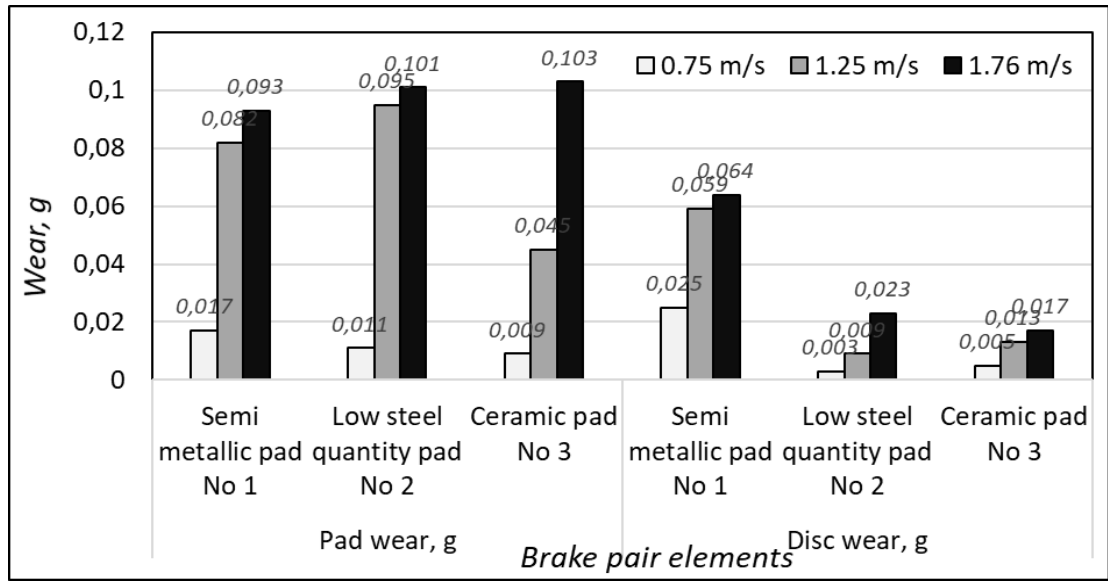

Fig. 3. Brake pad and disc wear during test ( 0.85 MPa contact pressure) 
The slowest increasing of the temperature appeared in the friction pair of brake discs with semi-metallic (No. 1) and low steel quantity (No. 2) blocks. The fastest increasing of the temperature appeared where brake disc was in the pair with ceramic pads No. 3 (Fig. 4).

The temperature difference of the discs used with ceramic and semi-metal and low steel quantity pads becomes apparent after 4 min of operation. Meanwhile, the temperature difference of discs working with semimetal and low-metal blocks becomes noticeable after $6 \mathrm{~min}$ of sliding. During $10 \mathrm{~min}$ of sliding, the temperature of the discs tested with different friction materials varied up to $40^{\circ} \mathrm{C}$ (Fig. 4).

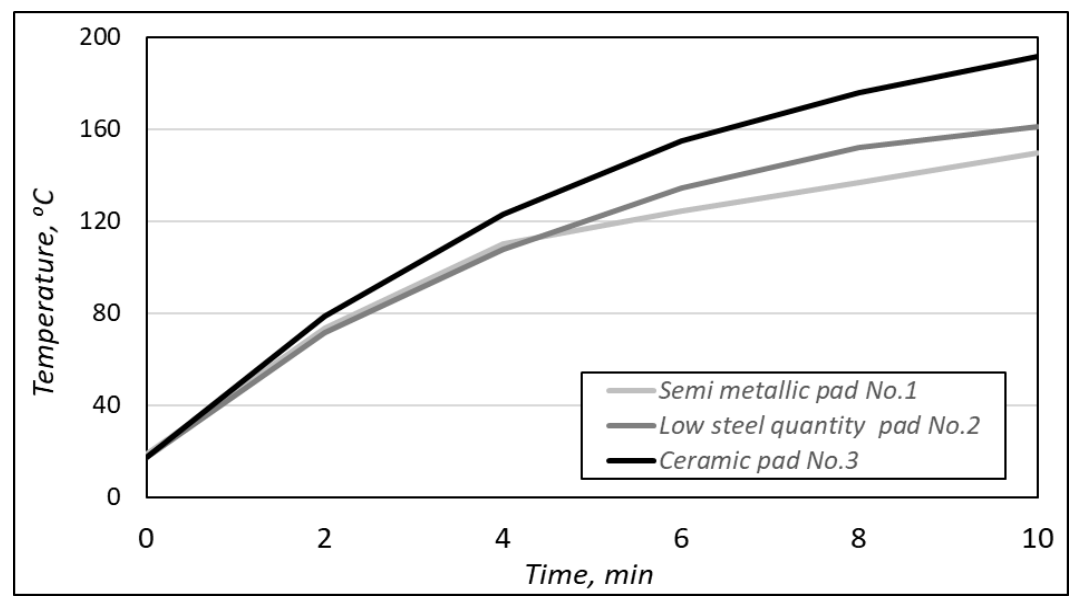

Fig. 4 Temperature of the brake discs during the testing of the pads of varied materials (sliding speed $1.75 \mathrm{~m} / \mathrm{s}$ and contact pressure $0.85 \mathrm{MPa}$ )

During the tests, the fixed braking torque of the friction machine was converted to the coefficient of friction according to formula (1). The coefficient of friction variation shown in Fig. 5.

The maximum values of the coefficient of friction (braking torque) are $0.345-0.435$, recorded when the brake disc is working with ceramic brake pads No. 3 (Fig. 5). The results showed that semi metallic brake pads No. 1 worked unstable: the values of the coefficient of friction increased, and in the working range of 2.5-3.0 min, the coefficient of friction drastically reduce, occurred vibration. This phenomenon stabilized within one minute, but the work of the friction pair was not stable.

When the brake disc is working with low steel quantity pads No. 2, the value of the coefficient of friction increased to $4 \mathrm{~min}$. The values of the friction coefficients of all investigated friction pairs started to decrease after 4-5 min of sliding time. The most likely cause is because of the increased temperature in the friction pair. The values of the coefficient of friction of low steel and semi metallic friction blocks are equal at the end of the test (0.31-0.32). Ceramic blocks have a higher coefficient of friction by 0.1 at the all testing time (Figure 5).

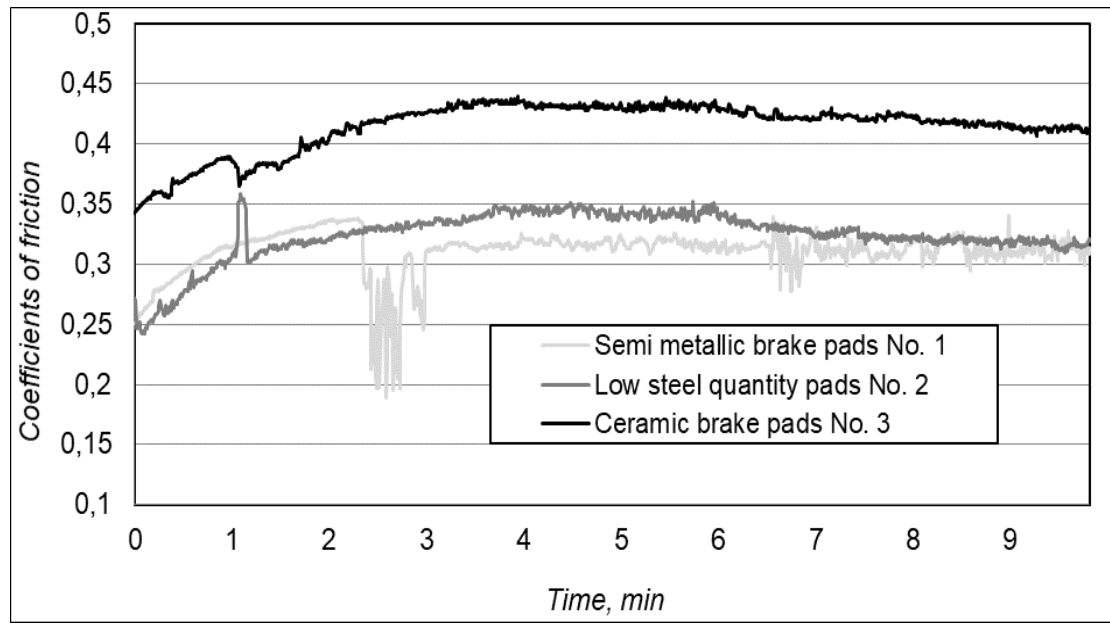

Fig. 5 Variation of the coefficient of friction during testing $(1.75 \mathrm{~m} / \mathrm{s})$

The average friction coefficients of the brake friction pairs are given in Table 1. 
Average values of coefficients of friction of brake friction pairs

Table 1

\begin{tabular}{|c|c|c|c|}
\hline \multirow{2}{*}{ Brake pad number } & \multicolumn{3}{|c|}{ Average coefficient of friction at slip speed } \\
\cline { 2 - 4 } & $0.75 \mathrm{~m} / \mathrm{s}$ & $1.26 \mathrm{~m} / \mathrm{s}$ & $1.76 \mathrm{~m} / \mathrm{s}$ \\
\hline Semi metallic pad (No. 1) & 0.23 & 0.33 & 0.31 \\
\hline Low steel quantity pad (No. 2) & 0.27 & 0.32 & 0.32 \\
\hline Ceramic pad (No. 3) & 0.34 & 0.41 & 0.41 \\
\hline
\end{tabular}

A significant increase in the coefficient of friction of all friction pairs is seen with an increase of sliding speed from 0.75 to $1.26 \mathrm{~m} / \mathrm{s}$ (from 18.5 to $43 \%$ ). Increasing the sliding speed in the friction pairs (No.1 and No. 3) from 1.26 to $1.76 \mathrm{~m} / \mathrm{s}$, the average coefficients of friction did not change, while friction pairs with semi metallic pads (No. 2) has lower coefficient of friction by $6.1 \%$.

\section{Conclusions}

As a result of our research, can be concluded:

1. Increasing the working speed of friction pairs from 0.75 to $1.25 \mathrm{~m} / \mathrm{s}$ increases the wear of blocks by 5.0-8.6 times; the biggest advantage of the ceramic block is at a sliding speed of $1.25 \mathrm{~m} / \mathrm{s}$ due to 2 times lower wear loss;

2. The semi metallic pads (No. 1) operated brake disc wears most intensively, while the disc worked with ceramic pads (No. 3) showed the lowest wear loss result;

3. The analysis of the dependences of the coefficient of friction and the temperature of the discs shows that with the increase of the temperature of working surface to $105-120{ }^{\circ} \mathrm{C}$, the coefficient of friction increases, but when these values are exceeded, it starts to decrease;

4. The highest temperature of brake disc appear when working with ceramic brake pads, as well as the highest coefficient of friction is achieved when the disc worked with ceramic brake pads;

5. Ceramic brake pads provide about 0.1 higher coefficient of friction $(0.41)$ compared to semi metallic and low steel quantity pads and gray cast iron brake disc (coefficients of friction in the range of $0.31-0.33$ ).

\section{References}

1. İskaitinių eismo ịvykių statistika Lietuvoje, 2013-2016 m., 2017 m. Vilnius, 11 p. Lietuvos automobilių kelių direkcija prie LR Susisiekimo ministerijos [2018-02-09] (Statistics of credit traffic accidents in Lithuania, 2013-2016, 2017 Vilnius, 11 p. Lithuanian Road Administration under the Ministry of Transport and Communications of the Republic of Lithuania) https://lakd.lrv.lt/lt/

2. Shinde H.S. (2017) Structural Analysis of Disc Brake Rotor for Different Materials. International Research Journal of Engineering and Technology. Vol. 04 (07). 2129-2135.

3. Hulskotte J.H.J., Roskam G.D., Denier van der Gon H.A.C. (2014) Elemental composition of current automotive braking materials andderived air emission factors. - Atmospheric Environment. - Vol.99. - P. 436445.

4. Bijwe J. (1997) Composites as Friction Materials: Recent Developments in Non Asbestos Fiber Reinforced Friction Materials. - Vol.18. - P. 378-396.

5. Yevtushenko A.A., Grzes P. (2012) Axisymmetric FEA of temperature in a pad/disc brake system at temperature-dependent coefficients of friction and wear. - International Communications in Heat and Mass Transfer. - Vol.39. - P. 1045-1053.

6. Verma P. Ch., Menapace L., Bonfanti A., Ciudin R., Gialanella S., Straffelini G. (2015) Braking paddisc system: Wear mechanisms and formation of wear fragments. Wear, Vol.322-323. - P.251-258.

7. Rampin I., Zanon M., Echeberria J., Martinez A.M., Loreto A. (2014) Development of copper-freelow steel brake pads for passenger cars. Conference: EuroBrake (Lille, France). 1-11 p.

8. Chan D., Stachowiak G.W. (2004) Review of automotive brake friction materials. - Proceedings of the Institution of Mechanical Engineers, Part D: Journal of Automobile Engineering. Vol.218, - P.953-966.

9. Erikson M., Jacobson S. (2000) Tribological surfaces of organic brake pads. - Tribology International. - Vol.33, - P. 817-827.

10. Masoud I. M., Al-Jarrah J. A., Abu Mansour T. (2014) Manufacturing of Gray Cast Iron Automotive Disc Brake. Indian journal of applied research. Engineering. Vol. 4 (3). 129-131. 